\title{
Clinicopathological features and outcomes of major salivary gland mucoepidermoid carcinoma: do they vary in different age groups
}

\author{
Yujiao $\mathrm{Li}^{1,2}$, Chaosu $\mathrm{Hu}^{1,2}$ \\ ${ }^{1}$ Department of Radiation Oncology, Fudan University Shanghai Cancer Center, Shanghai, China; ${ }^{2}$ Department of Oncology, Shanghai Medical \\ College, Shanghai, China \\ Contributions: (I) Conception and design: All authors; (II) Administrative support: All authors; (III) Provision of study materials or patients: All \\ authors; (IV) Collection and assembly of data: All authors; (V) Data analysis and interpretation: All authors; (VI) Manuscript writing: All authors; (VII) \\ Final approval of manuscript: All authors. \\ Correspondence to: Pro. Chaosu Hu. Fudan University Shanghai Cancer Center, 270 Dong An Road, Shanghai 200032, China. Email: hucsu62@yahoo.com.
}

\begin{abstract}
Background: The aim of this study was to analyze clinicopathological characteristics and prognostic value of age stratification for in patients with major salivary gland mucoepidermoid carcinoma (MSG-MEC).

Methods: MSG-MEC patients were extracted from the Surveillance, Epidemiology and End Results (SEER) database between 2010 and 2014. We examined the clinicopathological variables using Chi-squared tests. Univariate and multivariate analyses were performed to determine the effects of each variable on survival.

Results: A total of 729 patients were analyzed. Younger patients tended to be female and present with low grade disease and less-advanced $\mathrm{N}$ classification $(\mathrm{P}<0.05)$. In multivariate analyses, the patients aged 5-19 had better survival rates, and the risk of death became higher with increasing age. Compared to patients aged 80-95-years-old, the hazard ratios for patients aged 5-19, 20-29, 30-39, 40-49, 50-59, 60-69 and 70-79 years old were 0.000 [95\% confidence interval (CI): 0.000->1,000), 0.187 (95\% CI: 0.041-0.854), 0.172 (95\% CI: $0.039-0.771$ ), 0.006 (95\% CI: 0.010-0.361), 0.310 (95\% CI: 0.140-0.685), 0.541 (95\% CI: 0.261-1.121) and 0.440 (95\% CI: $0.230-0.840$ ), respectively. Subgroups analysis shows that the effect of advancing age was significantly associated with a higher risk of poor survival in Caucasian who harbored N0 classification $(\mathrm{P}<0.001)$, non-metastatic disease $(\mathrm{P}<0.001)$ or received surgery $(\mathrm{P}<0.001)$.

Conclusions: Younger patients tended to be female and present with low grade disease and less-advanced $\mathrm{N}$ classification. The risk of death became higher with increasing age. However, when considering patients affected by more aggressive disease, age was not significantly associated with higher risk of dying from MSG-MEC. In high-risk patients, tumor characteristics rather than age should be considered when making treatment decisions.
\end{abstract}

Keywords: Major salivary gland mucoepidermoid carcinoma (MSG-MEC); clinicopathological features; prognosis; age stratification

Submitted May 27, 2020. Accepted for publication Oct 21, 2020.

doi: 10.21037/tcr-20-2197

View this article at: http://dx.doi.org/10.21037/tcr-20-2197

\section{Introduction}

Salivary glands carcinomas comprise a morphologically diverse group of rare tumors of unknown cause $(1,2)$. These malignant tumors account for 0.4-2.6 cases per 100,000 people in the USA. According to the National Cancer Data Base Report on Cancer of the Head and Neck in the USA, major salivary gland tumors accounted for $6 \%$ of all malignant tumours in the head and neck and $0.3 \%$ of all malignancies (2,3). Mucoepidermoid carcinoma (MEC) is the most common reported pathology of parotid cancer, comprising approximately $30 \%$ of all salivary malignancies (4). Approximately $60 \%$ of MECs originate from the major salivary glands (MSG), and the parotid 
gland is the predominant site (5).

Several studies have described the association between the clinicopathological characteristics, including age, tumor size, tumor grade, tumor stages at presentation, and lymph node or distant metastases and clinical outcomes of MSG-MEC. Surgery has been the principal treatment modality for salivary glands mucoepidermoid carcinoma and postoperative radiotherapy has been used for close or positive resection margins, high-grade tumors, T3-4 tumors, and neck node metastases (6).

The age distribution of MSG-MEC is unimodal, peaking in individuals aged between 45.78-57 years old (7-10). Whether different age groups of patients with MSG-MECs have different survival outcomes remains controversial. Koul et al. found that age $>60$ years were statistically significant predictor of disease-specific survival (11). However, Hocwald et al. showed that age had no effect on survival outcomes for patients older than 50 years old (12). Kupferman et al. showed the favorable results among pediatric patients $(<19$-years-old) with salivary gland malignancies, with marginal long-term complications (13). However, since MSG-MECs are relatively rare, we queried the Surveillance, Epidemiology, and End Results (SEER) database. Therefore, the objective of this study is to assess the clinicopathological features and prognostic value of age on overall survival (OS) and cancer-specific survival (CSS) for MSG-MEC patients. We present the following article in accordance with the STROBE reporting checklist (available at http://dx.doi.org/10.21037/tcr-20-2197).

\section{Methods}

\section{Ethical statement}

The study was conducted in accordance with the Declaration of Helsinki (as revised in 2013). The study was approved by Fudan University Shanghai Cancer Center Ethics committee (reference number 1410 140-8). Written informed consent was obtained from all individual participants included in the study.

\section{Cobort population}

We obtained data from the current SEER database, which consists of 18 population-based cancer registries, and the grading systems were based on grade codes in ICD-O-3. This database collects and publishes cancer prevalence and survival data covering approximately $28 \%$ of the total population in the United States. SEER*Stat Version 8.3.4 (http://www. seer.cancer.gov/seerstat) from the National Cancer Institute was used to identify eligible patients in this study. Because the SEER database began collecting information on the presence or absence of metastases at the time of diagnosis in 2010, we included patients diagnosed with microscopically confirmed MSG-MEC between 1 January 2010 and 31 December 2014. We selected patients with only one primary malignancy in their lifetime. We excluded patients mainly because of lack of pathology type of tumor, unknown racial information, unstaged tumors or 'blanks' metastatic site. In total, 729 MSG-MEC patients were eligible for inclusion in the prevalence analyses.

\section{Statistical analysis}

Descriptive statistics were used to examine the baseline characteristics of the patients. The primary study outcomes were OS and CSS. OS was defined as time to the date of death due to any cause or the date of last follow-up. CSS was defined as time from initial treatment to death due to cancer. Kaplan-Meier survival curves were compared using the log-rank test. Hazard analysis was conducted using the Cox proportional hazards model. SPSS software, version 22.0 (SPSS, Chicago, IL, USA) was used for additional data processing. A probability value (P value) of $<0.05$ was considered statistically significant for all tests.

\section{Results}

\section{Clinical characteristics of all patients}

Data for a total of 729 patients (361 males and 368 females) were investigated. The median age was 54 years (range, 5-95 years). 41 (5.6\%), 68 (9.3\%), 84 (11.5\%), 106 (14.5\%), 146 (20.0\%), $132(18.1 \%), 98(13.4 \%)$ and $54(7.4 \%)$ patients were aged 5-19, 20-29, 30-39, 40-49, 50-59, 60-69, 70-79 and 80-96 years old, respectively. Among the cohort of the patients, $28.9 \%, 45.3 \%$ and $25.8 \%$ tumors were well differentiated (Grade I), moderately differentiated (Grade II) and poorly/undifferentiated differentiated (Grade III), respectively.

According to the 7th edition of UICC/AJCC Staging System, 335 patients $(46.0 \%)$ were T1, 205 patients $(28.1 \%)$ were T2, 111 patients $(15.2 \%)$ were T3, 78 patients $(10.7 \%)$ were $\mathrm{T} 4$. With regard to $\mathrm{N}$ classifications, 597 patients $(81.9 \%)$ were N0, 62 patients $(8.5 \%)$ were N1, 67 patients $(9.2 \%)$ were N2, and 3 patients $(0.4 \%)$ were N3. Patients 
with parotid gland carcinoma were more than eighty percent of all patients (85.2\%). Younger patients tended to be female and present with low grade disease and lessadvanced $\mathrm{N}$ classification $(\mathrm{P}<0.05)$. The clinicopathological features stratified by age at diagnosis are listed in Table 1 .

\section{Survival}

The overall mean follow-up of all patients in the cohort was 26.0 months (range, 0-59 months). Since the time of follow-up is short, we estimated the 3 -year OS and CSS for patients. In the univariate analysis, gender, age, tumor grade, $\mathrm{T}$ category, $\mathrm{N}$ category, distant metastases and surgery therapies were significantly associated with OS and CSS $(\mathrm{P}<0.05)$. The patients aged $15-29$ had better survival rates, and the risk of death became higher with increasing age (Table 2).

Gender, age, race, grade, T classification, N classification, surgery therapies and distant metastases were selected in the multivariate model. Gender, age, race, grade, $\mathrm{N}$ classification, surgery therapies and distant metastases were all independent prognostic factors in the multivariable analysis (Table 3). Compared to patients aged 80-95-yearsold, the hazard ratios for patients aged 5-19, 20-29, 30-39, 40-49, 50-59, 60-69 and 70-79 years old were 0.000 [95\% confidence interval (CI): 0.000->1,000], 0.187 (95\% CI: 0.041-0.854), 0.172 (95\% CI: 0.039-0.771), 0.006 (95\% CI: $0.010-0.361), 0.310$ (95\% CI: $0.140-0.685), 0.541$ (95\% $0.261-1.121)$ and 0.440 (95\% CI: $0.230-0.840)$, respectively.

\section{Subgroup analysis of the relationship between age and survival}

Multivariate Cox regression analysis demonstrated that variables, including gender, age, race, grade, $\mathrm{N}$ classification, surgery therapies and distant metastases were all independent prognostic factors of OS and CSS. To rule out the effects of these variables and further validate the effect of age on OS and CSS, we conducted the subgroup analysis based on these variables (Table 4). Remarkably, subgroups analysis shows that the effect of advancing age was significantly associated with a higher risk of poor survival in Caucasian who harbored N0 classification $(\mathrm{P}<0.001)$, non-metastatic disease $(\mathrm{P}<0.001)$ or received surgery $(\mathrm{P}<0.001)$.

\section{Discussion}

In this study, 729 patients with major salivary glands MEC were evaluated and we observed different age groups have distinct clinical manifestations. For instance, similar to results from other series, younger patients tended to be female and older patients tended to be male (14-16). These findings raise the possibility that hormonal influences may be important to the development of MECs. The evidence linking carcinomas of the major salivary glands to occupational exposures is sparse, and it is plausible that the more prominent rise in incidence of carcinomas of the major salivary glands at older ages among males compared to females, may reflect occupational exposures in maledominated jobs.

In the present study, younger patients tended to present with low grade disease. Brandwein et al. (17) and Liu et al. (18) also reported the mean age to be lowest among patients with a low-grade tumor, while those with a highgrade tumor were older, which is similar to results from our series.

Several studies have reported age was significantly associated with OS. However, a myriad of cut-off points have been employed, including $56,40,62$, or 50 -yearsold $(6,11,12,19,20)$. Koul et al. found that age $>60$ years were statistically significant predictor of disease-specific survival (11). However, Hocwald et al. showed that age had no effect on survival outcomes for patients older than 50 years old (12). Kupferman et al. showed the favorable results among pediatric patients (<19-yearsold) with salivary gland malignancies, with marginal long-term complications (13). The conflicting results may be related to the heterogeneity of the patients' cohorts, sample size, different treatment strategies and critical point definitions. However, all these authors did not further analyze the impact of different age groups. Our study classified all patients using 8 age groups and further clarifies the clinical manifestations and treatment outcomes according to age stratification.

A variety of factors may influence the effect of age on survival. More younger patients received surgery, radiotherapy and chemotherapy, and were less likely to have serious comorbidities, such as cardiovascular and pulmonary diseases, resulting a higher treatment completion rate and better treatment outcome (21). Additionally, older age is associated with decreased immune function, which not only promote the development of cancer, but also weaken the hosts' immune response to disease. In our study, we assessed CSS as the end-point to reduce the potential impact of deaths not related to cancer and our study suggests the patients aged 5-19 had better survival rates, and the risk of 
Table 1 Demographic characteristics of patients stratified by age at diagnosis

\begin{tabular}{|c|c|c|c|c|c|c|c|c|c|c|c|}
\hline Features & $\mathrm{n}$ & $\%$ & $5-19, \mathrm{n}$ & $20-29, \mathrm{n}$ & $30-39, \mathrm{n}$ & $40-49, \mathrm{n}$ & $50-59, \mathrm{n}$ & $60-69, \mathrm{n}$ & $70-79, \mathrm{n}$ & $80-95, n$ & $\mathrm{P}$ \\
\hline Male & 368 & 50.5 & 15 & 30 & 29 & 54 & 75 & 81 & 50 & 34 & \\
\hline Female & 361 & 49.5 & 26 & 38 & 55 & 52 & 71 & 51 & 48 & 20 & \\
\hline Race & & & & & & & & & & & 0.000 \\
\hline Asian & 88 & 12.1 & 4 & 12 & 22 & 16 & 13 & 10 & 6 & 5 & \\
\hline African American & 94 & 12.9 & 2 & 9 & 14 & 19 & 25 & 18 & 5 & 2 & \\
\hline T classification & & & & & & & & & & & 0.059 \\
\hline $\mathrm{T} 1$ & 335 & 46.0 & 14 & 33 & 44 & 54 & 78 & 54 & 40 & 18 & \\
\hline $\mathrm{T} 4$ & 78 & 10.7 & 4 & 10 & 4 & 8 & 13 & 19 & 11 & 9 & \\
\hline $\mathrm{N}$ classification & & & & & & & & & & & 0.031 \\
\hline No & 597 & 81.9 & 34 & 58 & 78 & 95 & 120 & 100 & 71 & 41 & \\
\hline N1 & 62 & 8.5 & 2 & 4 & 4 & 4 & 10 & 17 & 12 & 9 & \\
\hline N2 & 67 & 9.2 & 4 & 6 & 2 & 7 & 15 & 15 & 14 & 4 & \\
\hline N3 & 3 & 0.4 & 1 & 0 & 0 & 0 & 1 & 0 & 1 & 0 & \\
\hline Grade & & & & & & & & & & & 0.000 \\
\hline 1 & 211 & 28.9 & 19 & 27 & 26 & 35 & 47 & 33 & 17 & 7 & \\
\hline Multiple & 3 & 0.4 & 0 & 0 & 0 & 2 & 0 & 1 & 0 & 0 & \\
\hline Surgery therapy & & & & & & & & & & & 0.000 \\
\hline Yes & 712 & 97.7 & 41 & 68 & 84 & 101 & 145 & 128 & 98 & 47 & \\
\hline No & 17 & 2.3 & 0 & 0 & 0 & 5 & 1 & 4 & 0 & 7 & \\
\hline Tumor location & & & & & & & & & & & 0.606 \\
\hline Parotid gland & 621 & 85.2 & 38 & 60 & 66 & 92 & 120 & 110 & 87 & 48 & \\
\hline Submandibular gland & 84 & 11.5 & 3 & 7 & 13 & 8 & 20 & 16 & 11 & 6 & \\
\hline Sublingual gland & 8 & 1.1 & 0 & 0 & 1 & 2 & 3 & 2 & 0 & 0 & \\
\hline Major salivary gland, NOS & 16 & 2.2 & 0 & 1 & 4 & 4 & 3 & 4 & 0 & 0 & \\
\hline
\end{tabular}

NOS, not otherwise specified. 
Table 2 Survival analysis of overall survival and cancer-specific survival of MSG-MEC

\begin{tabular}{|c|c|c|c|c|}
\hline \multirow[t]{2}{*}{ Prognostic factor } & \multicolumn{2}{|c|}{$\begin{array}{l}\text { 3-y overall } \\
\text { survival }\end{array}$} & \multicolumn{2}{|c|}{$\begin{array}{c}\text { 3-y cancer-specific } \\
\text { survival }\end{array}$} \\
\hline & $\%$ & $\mathrm{P}$ & $\%$ & $P$ \\
\hline Gender & & $<0.001$ & & $<0.001$ \\
\hline Male & 80.3 & & 82.8 & \\
\hline Female & 93.4 & & 96.4 & \\
\hline Age & & $<0.001$ & & $<0.001$ \\
\hline $5-19$ & 100.0 & & 100.0 & \\
\hline 20-29 & 95.1 & & 95.1 & \\
\hline 30-39 & 96.7 & & 100.0 & \\
\hline $40-49$ & 96.4 & & 96.4 & \\
\hline $50-59$ & 92.2 & & 92.2 & \\
\hline $60-69$ & 76.3 & & 80.9 & \\
\hline 70-79 & 77.2 & & 79.9 & \\
\hline 80-95 & 61.9 & & 72.6 & \\
\hline Race & & 0.026 & & 0.078 \\
\hline Caucasian & 84.8 & & 87.9 & \\
\hline Asian & 92.9 & & 94.4 & \\
\hline African American & 93.3 & & 94.8 & \\
\hline Grade & & $<0.001$ & & $<0.001$ \\
\hline 1 & 99.4 & & 100 & \\
\hline 2 & 94.4 & & 97.0 & \\
\hline 3 & 60.1 & & 63.6 & \\
\hline T classification & & $<0.001$ & & $<0.001$ \\
\hline $\mathrm{T} 1$ & 96.5 & & 97.9 & \\
\hline T2 & 88.4 & & 91.3 & \\
\hline T3 & 66.0 & & 71.4 & \\
\hline $\mathrm{T} 4$ & 70.3 & & 72.9 & \\
\hline $\mathrm{N}$ classification & & $<0.001$ & & $<0.001$ \\
\hline NO & 93.4 & & 96.0 & \\
\hline $\mathrm{N} 1$ & 56.5 & & 59.0 & \\
\hline N2 & 58.5 & & 62.1 & \\
\hline N3 & 66.7 & & 66.7 & \\
\hline
\end{tabular}

Table 2 (continued)
Table 2 (continued)

\begin{tabular}{|c|c|c|c|c|}
\hline \multirow{2}{*}{ Prognostic factor } & \multicolumn{2}{|c|}{$\begin{array}{l}\text { 3-y overall } \\
\text { survival }\end{array}$} & \multicolumn{2}{|c|}{$\begin{array}{c}\text { 3-y cancer-specific } \\
\text { survival }\end{array}$} \\
\hline & $\%$ & $\mathrm{P}$ & $\%$ & $\mathrm{P}$ \\
\hline Tumor location & & 0.733 & & 0.813 \\
\hline Parotid gland & 86.2 & & 89.1 & \\
\hline Submandibular gland & 90.2 & & 91.6 & \\
\hline Sublingual gland & 100 & & 100 & \\
\hline $\begin{array}{l}\text { Major salivary gland, } \\
\text { NOS }\end{array}$ & 83.3 & & 88.9 & \\
\hline Surgery therapy & & $<0.001$ & & $<0.001$ \\
\hline Yes & 88.1 & & 90.7 & \\
\hline No & 30.3 & & 35.1 & \\
\hline Distant metastases & & $<0.001$ & & $<0.001$ \\
\hline No & 88.3 & & 91.1 & \\
\hline Single & 14.3 & & 14.3 & \\
\hline Multiple & 0 & & 0 & \\
\hline
\end{tabular}

death became higher with increasing age. These findings suggest that MSG-MEC in younger adults exhibits distinct biological behavior. One theory partly explains the increased incidence of cancer in the elderly is that in the context of immune aging and long-term exposure to environmental factors such as tobacco or alcohol. This difference in exposure and immune aging may lead to biological differences in solid tumors between older patients and younger patients (22-24).

This is the first population-based analysis assessing clinicopathological features and prognostic value of age on OS and CSS for MSG-MEC patients. Some limitations of our study should be acknowledged. First of all, retrospective analysis may contribute to some bias. Second, the lack of data on additional predictors of OS such as performance status, comorbidities, tobacco smoking and alcohol consumption, prevented us to adjust our analyses for these important factors. Finally, also due to the data limitations of the SEER database, local invasion, tumor size and positive surgical margins at final pathology were not able to be analyzed between age at diagnosis and CSS in this study. 
Table 3 Multivariable logistic regression for OS and CSS in the SEER cohort

\begin{tabular}{|c|c|c|c|c|c|c|c|c|}
\hline Prognostic factor & \multicolumn{4}{|c|}{ Overall survival } & \multicolumn{4}{|c|}{ Cancer-specific survival } \\
\hline Age & 0.000 & & & & 0.024 & & & \\
\hline $5-19$ & & 0.000 & 0.000 & $>1,000$ & & 0.901 & 0.169 & 4.800 \\
\hline $20-29$ & & 0.188 & 0.041 & 0.862 & & 0.928 & 0.218 & 3.960 \\
\hline 30-39 & & 0.208 & 0.045 & 0.956 & & 0.914 & 0.217 & 3.853 \\
\hline $50-59$ & & 0.315 & 0.142 & 0.697 & & 0.937 & 0.266 & 3.294 \\
\hline $60-69$ & & 0.480 & 0.247 & 0.933 & & 0.946 & 0.263 & 3.403 \\
\hline $70-79$ & & 0.541 & 0.258 & 1.136 & & 0.958 & 0.249 & 3.687 \\
\hline 80-95 & & 1 (reference) & & & & 1 (reference) & & \\
\hline Grade & 0.000 & & & & & 0.000 & & \\
\hline 1 & & 0.055 & 0.007 & 0.424 & & 0.884 & & \\
\hline 2 & & 0.338 & 0.165 & 0.692 & & 0.886 & 0.335 & 2.331 \\
\hline 3 & & 1 (reference) & & & & 1 (reference) & 0.370 & 2.121 \\
\hline T classification & 0.147 & & & & & 0.194 & & \\
\hline $\mathrm{T} 1$ & & 0.679 & 0.291 & 1.582 & & 1.008 & 0.350 & 2.903 \\
\hline T2 & & 1.107 & 0.517 & 2.371 & & 1.007 & 0.344 & 2.946 \\
\hline T3 & & 1.989 & 1.017 & 3.890 & & 1.063 & 0.340 & 3.327 \\
\hline N3 & & 1 (reference) & & & & 1 (reference) & & \\
\hline Surgery therapy & 0.019 & & & & 0.035 & & & \\
\hline Yes & & 0.293 & 0.106 & 0.808 & & 0.789 & 0.078 & 8.003 \\
\hline No & & 1 (reference) & & & & 1 (reference) & & \\
\hline Distant metastases & 0.000 & & & & 0.000 & & & \\
\hline No & & 0.003 & 0.000 & 0.032 & & 0.000 & 0.000 & 0.201 \\
\hline Single & & 0.010 & 0.001 & 0.093 & & 0.000 & 0.000 & 0.429 \\
\hline Multiple & & 1 (reference) & & & & 1 (reference) & & \\
\hline Race & 0.011 & & & & 0.009 & & & \\
\hline Caucasian & & 3.505 & 1.087 & 11.301 & & 1.045 & 0.443 & 2.464 \\
\hline Asian & & 2.405 & 0.512 & 11.292 & & 1.028 & 0.320 & 3.302 \\
\hline African American & & 1 (reference) & & & & 1 (reference) & & \\
\hline
\end{tabular}

$\mathrm{P}$ values were calculated using an adjusted Cox proportional-hazards model. OS, overall survival; CSS, cancer-specific survival; Cl, confidence interval; HR, hazard ratio. 
Table 4 The effect of age on OS and CSS based on different subgroup variables

\begin{tabular}{|c|c|c|c|c|c|c|c|c|}
\hline Prognostic factor & \multicolumn{4}{|c|}{ Overall survival } & \multicolumn{4}{|c|}{ Cancer-specific survival } \\
\hline \multicolumn{9}{|l|}{ Gender } \\
\hline Male & 0.000 & 1.597 & 1.333 & 1.913 & 0.000 & 22.678 & 1.000 & 0.000 \\
\hline Female & 0.000 & 1.936 & 1.400 & 2.677 & 0.010 & 6.603 & 1.000 & 0.010 \\
\hline 1 & 0.253 & 15.251 & 0.142 & $1,636.270$ & Null & Null & Null & Null \\
\hline 2 & 0.002 & 1.707 & 1.208 & 2.412 & 0.021 & 5.328 & 1.000 & 0.021 \\
\hline 3 & 0.015 & 1.254 & 1.045 & 1.505 & 0.066 & 3.375 & 1.000 & 0.066 \\
\hline \multicolumn{9}{|l|}{ Race } \\
\hline African American & 0.541 & 1.224 & 0.641 & 2.336 & 0.891 & 1.051 & 0.515 & 2.148 \\
\hline \multicolumn{9}{|l|}{ T classification } \\
\hline $\mathrm{T} 1$ & 0.000 & 2.458 & 1.513 & 3.994 & 0.015 & 2.098 & 1.156 & 3.804 \\
\hline $\mathrm{T} 2$ & 0.000 & 1.981 & 1.393 & 2.819 & 0.003 & 1.833 & 1.227 & 2.738 \\
\hline T3 & 0.011 & 1.382 & 1.077 & 1.773 & 0.036 & 1.353 & 1.020 & 1.795 \\
\hline $\mathrm{T} 4$ & 0.029 & 1.335 & 1.030 & 1.730 & 0.041 & 1.365 & 1.013 & 1.839 \\
\hline \multicolumn{9}{|l|}{$\mathrm{N}$ classification } \\
\hline No & 0.000 & 2.232 & 1.685 & 2.956 & 0.000 & 2.450 & 1.605 & 3.740 \\
\hline Single & 0.510 & 1.147 & 0.763 & 1.724 & 0.510 & 1.147 & 0.763 & 1.724 \\
\hline Multiple & 0.582 & 13.018 & 0.001 & $>1,000$ & 0.582 & 13.018 & 0.001 & $>1,000$ \\
\hline \multicolumn{9}{|l|}{ Surgery therapy } \\
\hline Yes & 0.000 & 1.690 & 1.433 & 1.993 & 0.000 & 1.602 & 1.324 & 1.938 \\
\hline No & 0.228 & 1.317 & 0.842 & 2.060 & 0.248 & 1.347 & 0.812 & 2.235 \\
\hline
\end{tabular}

OS, overall survival; CSS, cancer-specific survival; $\mathrm{Cl}$, confidence interval; $\mathrm{HR}$, hazard ratio.

\section{Conclusions}

Younger patients tended to be female and present with low grade disease and less-advanced $\mathrm{N}$ classification. The risk of death became higher with increasing age. However, when considering patients affected by more aggressive disease, age was not significantly associated with higher risk of dying from MSG-MEC. In high-risk patients, tumor characteristics rather than age should be considered when making treatment decisions. 


\section{Acknowledgments}

We acknowledge the support of the Department of Radiation Oncology, Fudan University Shanghai Cancer Center. The views expressed in this publication are those of the authors.

Funding: None.

\section{Footnote}

Reporting Checklist: The authors have completed the STROBE reporting checklist. Available at http://dx.doi. org/10.21037/tcr-20-2197

Conflicts of Interest: Both authors have completed the ICMJE uniform disclosure form (available at http://dx.doi. org/10.21037/tcr-20-2197). Both authors have no conflicts of interest to declare.

Ethical Statement: The authors are accountable for all aspects of the work in ensuring that questions related to the accuracy or integrity of any part of the work are appropriately investigated and resolved. The study was conducted in accordance with the Declaration of Helsinki (as revised in 2013). The study was approved by Fudan University Shanghai Cancer Center Ethics committee (reference number 1410 140-8). Written informed consent was obtained from all individual participants included in the study.

Open Access Statement: This is an Open Access article distributed in accordance with the Creative Commons Attribution-NonCommercial-NoDerivs 4.0 International License (CC BY-NC-ND 4.0), which permits the noncommercial replication and distribution of the article with the strict proviso that no changes or edits are made and the original work is properly cited (including links to both the formal publication through the relevant DOI and the license). See: https://creativecommons.org/licenses/by-nc-nd/4.0/.

\section{References}

1. Eveson JW, Cawson RA. Salivary gland tumours. A review of 2410 cases with particular reference to histological types, site, age and sex distribution. J Pathol 1985;146:51-58.

2. Qin BD, Jiao X, Liu K, et al. Clinical, pathological and treatment factors associated with the survival of patients with primary pulmonary salivary gland-type tumors. Lung Cancer 2018;126:174-81.

3. Pinkston JA, Cole P. Incidence rates of salivary gland tumors: Results from a population-based study. Otolaryngol Head Neck Surg 1999;120:834-40.

4. Liu $S, O w A$, Ruan $M$, et al. Prognostic factors in primary salivary gland mucoepidermoid carcinoma: An analysis of 376 cases in an Eastern Chinese population. Int J Oral Maxillofac Surg 2014;43:667-73.

5. Park G, Lee S. Postoperative radiotherapy for mucoepidermoid carcinoma of the major salivary glands: Long-term results of a single-institution experience. Radiat Oncol J 2018;36:317-24.

6. Iqbal H, Bhatti ABH, Hussain R, et al. Ten year experience with surgery and radiation in the management of malignant major salivary gland tumors. Asian Pac J Cancer Prev 2014;15:2195-9.

7. Guevara-Canales JO, Morales-Vadillo R, Guzman-Arias G, et al. Mucoepidermoid carcinoma of the salivary glands. A retrospective study of 51 cases and review of the literature. Acta Odontol Latinoam 2016;29:230-8.

8. Villavicencio-Ayala B, Resendiz-Colosia JA, LabastidaAlmendaro S, et al. Prognostic factors in head and neck mucoepidermoid carcinoma. CIR CIR 2008;76:109-17.

9. Rapidis $\mathrm{AD}$, Givalos N, Gakiopoulou $\mathrm{H}$, et al. Mucoepidermoid carcinoma of the salivary glands. Review of the literature and clinicopathological analysis of 18 patients. Oral Oncol 2007;43:130-6.

10. Fu JY, Wu C, Shen S, et al. Salivary gland carcinoma in Shanghai (2003-2012): An epidemiological study of incidence, site and pathology. BMC Cancer 2019;19:350.

11. Koul R, Dubey A, Butler J, et al. Prognostic factors depicting disease-specific survival in parotid-gland tumors. Int J Radiat Oncol Biol Phys 2007;68:714-8.

12. Hocwald E, Korkmaz H, Yoo GH, et al. Prognostic factors in major salivary gland cancer. Laryngoscope 2001;111:1434-9.

13. Kupferman ME, de la Garza GO, Santillan AA, et al. Outcomes of pediatric patients with malignancies of the major salivary glands. Ann Surg Oncol 2010;17:3301-7.

14. Sun EC, Curtis R, Melbye M, et al. Salivary gland cancer in the United States. Cancer Epidemiol Biomarkers Prev 1999;8:1095-100.

15. Luukkaa H, Klemi P, Leivo I, et al. Salivary gland cancer in Finland 1991--96: An evaluation of 237 cases. Acta Otolaryngol 2005;125:207-14.

16. Boukheris H, Curtis RE, Land CE, et al. Incidence of carcinoma of the major salivary glands according to the 
WHO classification, 1992 to 2006: A Population-Based study in the united states. Cancer Epidemiol Biomarkers Prev 2009;18:2899-906.

17. Brandwein MS, Ivanov K, Wallace DI, et al.

Mucoepidermoid carcinoma: A clinicopathologic study of 80 patients with special reference to histological grading. Am J Surg Pathol 2001;25:835-45.

18. Liu S, Ow A, Ruan M, et al. Prognostic factors in primary salivary gland mucoepidermoid carcinoma: An analysis of 376 cases in an Eastern Chinese population. Int J Oral Maxillofac Surg 2014;43:667-73.

19. Akbaba S, Heusel A, Mock A, et al. The impact of age on the outcome of patients treated with radiotherapy for mucoepidermoid carcinoma (MEC) of the salivary glands in the head and neck: A 15-year single-center experience. Oral Oncol 2019;97:115-23.

Cite this article as: $\mathrm{Li} \mathrm{Y,} \mathrm{Hu} \mathrm{C.} \mathrm{Clinicopathological} \mathrm{features}$ and outcomes of major salivary gland mucoepidermoid carcinoma: do they vary in different age groups. Transl Cancer Res 2020;9(11):6691-6699. doi: 10.21037/tcr-20-2197
20. Lima RA, Tavares MR, Dias FL, et al. Clinical prognostic factors in malignant parotid gland tumors. Otolaryngol Head Neck Surg 2005;133:702-8.

21. Kim SA, Roh JL, Lee SA, et al. Pretreatment depression as a prognostic indicator of survival and nutritional status in patients with head and neck cancer. Cancer 2016;122:131-40.

22. Foster AD, Sivarapatna A, Gress RE. The aging immune system and its relationship with cancer. Aging Health 2011;7:707-18.

23. Pawelec G, Goldeck D, Derhovanessian E. Inflammation, ageing and chronic disease. Curr Opin Immunol 2014;29:23-8.

24. Wu D, Meydani SN. Age-associated changes in immune and inflammatory responses: Impact of vitamin E intervention. J Leukoc Biol 2008;84:900-14. 